
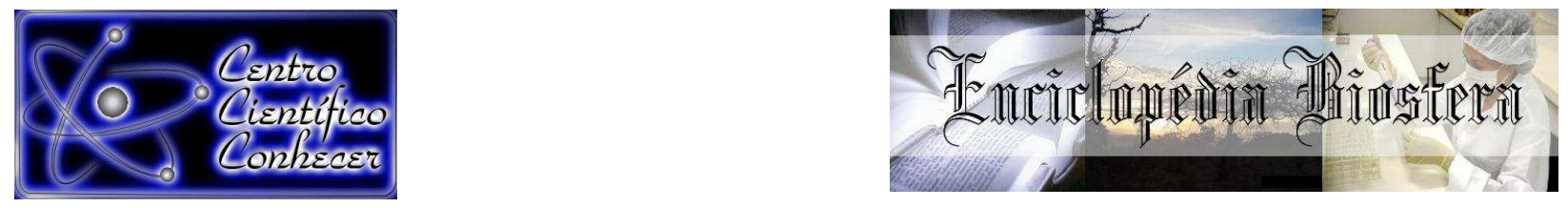

\title{
AVALIAÇÃO DO TEOR DE PROTEÍNA EM AMOSTRAS DE WHEY PROTEIN EM BRASÍLIA - DF
}

\author{
Erick Ricardo Marques de Oliveira ${ }^{1}$, Edina Costa de Sousa ${ }^{2}$, Alvaro Carlos Galdos- \\ Riveros $^{3}$ \\ ${ }^{1}$ Farmacêutico formado pela Faculdade Anhanguera de Brasília - DF \\ ${ }^{2}$ Laboratorista da Faculdade Anhanguera de Brasília - DF, \\ ${ }^{3}$ Docente do Instituto de Ciências da Saúde da Universidade Federal de Mato \\ Grosso, Sinop - MT (alvarogaldos@usp.br)
}

\section{Recebido em: 03/10/2016 - Aprovado em: 21/11/2016 - Publicado em: 05/12/2016 DOI: 10.18677/EnciBio 2016B 131}

\begin{abstract}
A busca por um corpo perfeito e/ou por uma melhor saúde e, por conseguinte, por uma melhor qualidade de vida, tem levado a busca pela suplementação alimentar, sendo a proteína do soro do leite, "Whey Protein", um dos recursos mais populares. Por outro lado, estudos que tenham investigado o conteúdo proteico destes suplementos ainda são demasiadamente escassos. Diante do exposto, o objetivo do presente estudo é verificar e comparar o conteúdo proteico entre os valores reportados pelo fabricante e os quantificados. Para tanto, seis marcas de Whey Protein, sendo estas, aparentemente, as mais utilizadas por praticantes de atividades físicas, determinadas como amostra A, B, C, D, E e F, foram analisadas. A quantificação do teor proteico foi realizada por meio do método de Kjeldahl. Todas as análises foram realizadas em triplicata. Os resultados da presente investigação sugerem que o teor proteico reportado pelos fabricantes parece ser menor do que aquele mensurado, sendo $-10,33,-21,09,-60,21,-46,21,-9,70,-17,74$, para as amostras A, B, C, D, E e F, respectivamente. Em conclusão, nenhuma das amostras analisadas demonstrou o mesmo teor proteico daquele reportado pelo fabricante.
\end{abstract}

PALAVRAS-CHAVE: Deficiência de Proteína, Fenômenos Fisiológicos da Nutrição, Rotulagem de Alimentos.

\section{PROTEIN CONTENT OF ASSESSMENT WHEY PROTEIN SAMPLES IN BRASILIA - DF}

\begin{abstract}
The search for a perfect body or for better health and therefore for a better quality of life, has led the search for food supplementation, and the whey protein, "Whey Protein", one of the most popular features. On the other hand, studies which have investigated the protein content of the supplements is still too scarce. Given the above, the objective of this study was to assess and compare the protein content between the values reported by the manufacturer and quantified. Therefore, six brands of whey protein, which are apparently the most used, named as sample A, B, $C, D, E$ and $F$ were analyzed. Quantification of protein content was carried out by the Kjeldahl method. All analyzes were carried out in triplicate. The results of this research suggest that the protein content reported by manufacturers seem to be
\end{abstract}


smaller than those measured, being -10.33, -21.09, -60.21, -46.21, $-9.70 \%,-1774$, for samples A, B, C, D, E and F, respectively. In conclusion, none of the samples showed the same protein content of that reported by the manufacturer.

KEYWORDS: Food Labelling, Nutritional Physiological Phenomena, Deficiency Protein.

\section{INTRODUÇÃO}

A falta de uma alimentação saudável e adequada tem acarretado grandes prejuízos para a saúde das pessoas. Crianças, jovens, adultos e idosos têm hoje uma série de problemas causados por uma má alimentação, principalmente pela falta de ingesta adequada de proteínas que são essenciais para o sistema imunológico (DEVRIES \& PHILLIPS, 2015) e no combate a processos inflamatórios no sistema músculo esquelético (DRAGANIDIS et al., 2016). De acordo com FARUP et al. (2014) o reparo, crescimento muscular e fonte energética para o metabolismo da musculatura esquelética estão relacionados com o consumo proteico e treinamento físico diário.

As proteínas estão diretamente relacionadas com a qualidade de vida, pois participam de quase todos os processos biológicos (transporte, armazenamento, regulação, defesa), desempenham funções vitais no organismo e estão entre as macromoléculas mais abundantes (DEVLIN, 2011). A busca por um corpo perfeito e por uma melhor qualidade de vida, suprindo essa falta de proteínas, tem levado a busca pela suplementação e um dos mais utilizados hoje tem sido a proteína do soro do leite, o chamado "Whey Protein". Esta é considerada atualmente como a melhor fonte proteica, utilizada por atletas e esportistas de todas as modalidades. Além disso, é bastante empregada na indústria alimentícia, na indústria de suplementos e fórmulas enterais (JAKUBOWICZ \& FROY, 2013).

A Whey Protein (WP) encontrada na parte líquida do leite é removida da caseína durante o processo de fabricação de queijos. Esta é comercializada em várias formas tais como, Whey Protein concentrada (WPC), Whey Protein isolada (WPI), Whey sem lactose, Whey hidrolisada parcialmente e totalmente e Whey protein desmineralizada (PAL \& RADAVELLI-BAGATINI, 2013).

Atletas, pessoas fisicamente ativas e até mesmo portadores de doenças, vêm procurando benefícios nessa fonte proteica (KRESSLER et al., 2014; DEVRIES \& PHILLIPS, 2015). Conforme LÖNNERDAL (2003), a WP possui peptídeos bioativos, que atuam como agentes antimicrobianos, anti-hipertensivos, reguladores da função imune, assim como fatores de crescimento. Estudos vêm demonstrando os benefícios da WP como fonte de suplementação para a falta de proteínas, este é extraído do soro do leite, na porção mais aquosa que é gerada no processo de fabricação do queijo. Nas propriedades terapêuticas foram descritas, como parte importante no tratamento e prevenção de flatulências, prisão de ventre e putrefação intestinal (SALZANO, 2002; TAHAVORGAR et al., 2014).

O consumo de WP antes ou com as refeições diminuíram significativamente a glicemia pós-prandial e melhoraram a resposta da insulina (AKHAVAN et al., 2014; ADAMS \& BROUGHTON, 2016). De acordo com TOSUKHOWONG et al. (2016) a ingesta de WP poderia beneficiar pacientes com doença de Parkinson, já que fortalece o potencial antioxidante, estimulando a síntese de proteína muscular e reduzem o risco de comprometimento cognitivo e demência. Já AJAREM et al. (2015) afirmam que a suplementação com WP desenvolve proteção aos neurônios do sistema nervoso central em camundongos diabéticos. 
Em idosos, tem sido indicada a utilização de WP, já que durante esta faixa etária sofrem com processos inflamatórios de grau baixo, porém crônicos. $O$ mecanismo de ação da WP é através do aumento de glutationa, melhora da atividade de enzimas antioxidantes (superóxido dismutase - SOD, catalase, glutationa peroxidase) (DRAGANIDIS et al., 2016). As proteínas do soro do leite, ou WP têm rápida digestão e absorção intestinal, o que proporciona elevação da concentração de aminoácidos no plasma, que, por sua vez, estimula a síntese proteica nos tecidos (BURD et al., 2012).

Por outro lado, no ano de 2013, a Agência Nacional de Vigilância Sanitária (ANVISA), demonstrou que diversos fabricantes comercializavam seus produtos informando um teor proteico aquém daquele mensurado. Ademais, estudos que tenham investigado 0 conteúdo proteico destes suplementos ainda são demasiadamente escassos. O objetivo deste trabalho foi analisar 0 teor de proteínas, conforme a RDC no 360/2003 (ANVISA, 2003), de seis marcas comercializadoras de WP em Brasília - DF.

\section{MATERIAL E MÉTODOS}

\section{Amostra Whey Protein}

Para este estudo foram analisadas 06 (seis) marcas de WP, hoje comercializadas, sendo as mais utilizadas por praticantes de atividades físicas, determinadas como amostra A, B, C, D, E e F. Todas as amostras foram submetidas aos testes em triplicata, no mesmo ambiente, temperatura e condições para evitar qualquer tipo de alteração. As proteínas estavam lacradas e dentro do prazo de validade (CECCHI, 2003).

\section{Determinação do Teor de proteína}

Para esta determinação foram utilizadas a metodologia de CECCHI (2013) com leves modificações. O procedimento mais utilizado para a determinação de proteínas é por meio da determinação de um elemento ou um grupo pertencente à proteína. A conversão para conteúdo de proteína é feita por meio de um fator, que é determinado para cada tipo de alimento. Os elementos analisados são carbono ou nitrogênio, e os grupos são aminoácidos e ligações peptídicas nesse caso o utilizado é a análise de nitrogênio, pois considera que as proteínas têm em média $16 \%$ de nitrogênio. O método escolhido para a análise das amostras de WP foi o mesmo relatado na RDC no 360/2003, item 3.3.2 da ANVISA (2003), que é o de Kjeldahl, usando como fator de conversão o valor de 6,38 referentes às proteínas lácteas.

Foram utilizados $200 \mathrm{mg}$ (valor preconizado no método de Kjeldahl) de cada amostra - Whey Protein, Ácido sulfúrico - $\mathrm{H}_{2} \mathrm{SO}_{4}$ concentrado (QUÍMICA MODERNA, lote: 02136); Hidróxido de sódio - NaOH 0,02M (Química MODERNA, lote: 122745); Hidróxido de sódio - NaOH concentrado (QUÍMICA MODERNA, lote: 122745); Ácido clorídrico - $\mathrm{HCl}$ concentrado (CHEMCO, lote: 25415); Ácido clorídrico - HCl 0,01M (CHEMCO, lote: 25415); Ácido Bórico 3\% (Química Moderna, lote: 01863); Solução indicadora (vermelho de metila 0,2\% + azul de metileno 0,2\%); Tiossulfato de sódio a 50\% (SYNTH, lote: 05592); Mistura de catalisadores: $96 \%$ de sulfato de potássio - $\mathrm{K}_{2} \mathrm{SO}_{4}+4 \%$ sulfato de cobre - $\mathrm{CuSO}_{4}(\mathrm{CHEMCO}$, lote: 21522$)$.

Os equipamentos foram buretas de $50 \mathrm{~mL}$ com suportes, bloco digestor de proteínas, balão volumétrico de $100 \mathrm{~mL}$, destilador de nitrogênio e proteína (NOVA TÉCNICA, MODELO NT415), capela (QUIMIS REF/MODELO 216 F20, № SÉRIE ENCICLOPÉDIA BIOSFERA, Centro Científico Conhecer - Goiânia, v.13 n.24; p.1426 2016 
009063) pipeta volumétrica, balança analítica (QUIMIS REF/MODELO 520,400,№ SÉRIE 1024020), frascos erlenmeyer de $50 \mathrm{~mL}, 125 \mathrm{~mL}$ e $250 \mathrm{~mL}$; tubos de Kjeldahl, filtro de papel e espátulas.

O método de Kjeldahl, utilizado para análise do teor de proteínas, consiste em três etapas: digestão da amostra, destilação e a titulação (Figura 1).

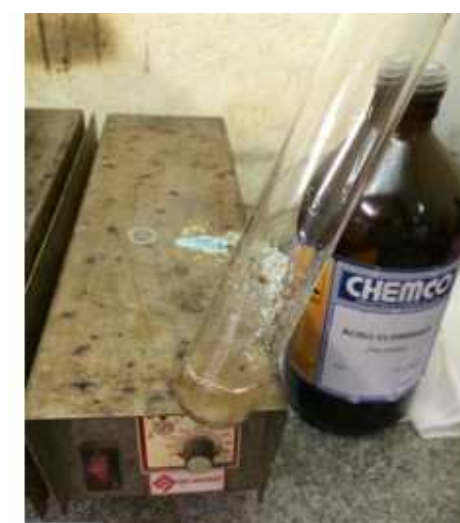

A

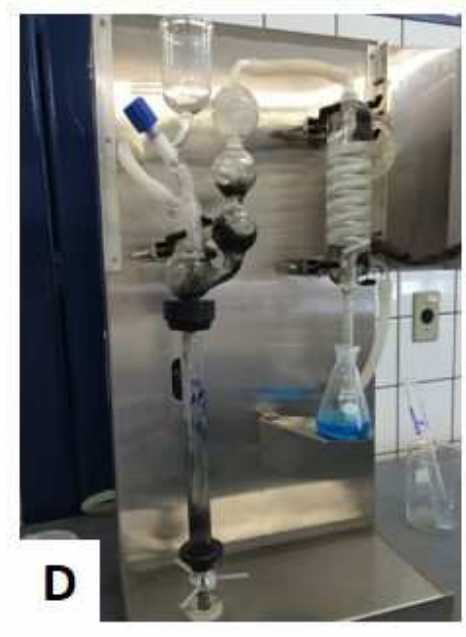

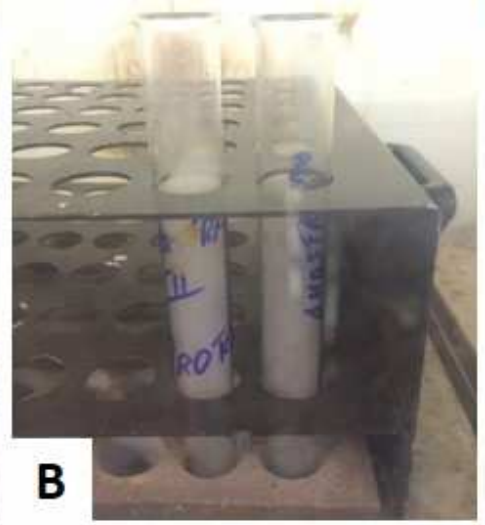
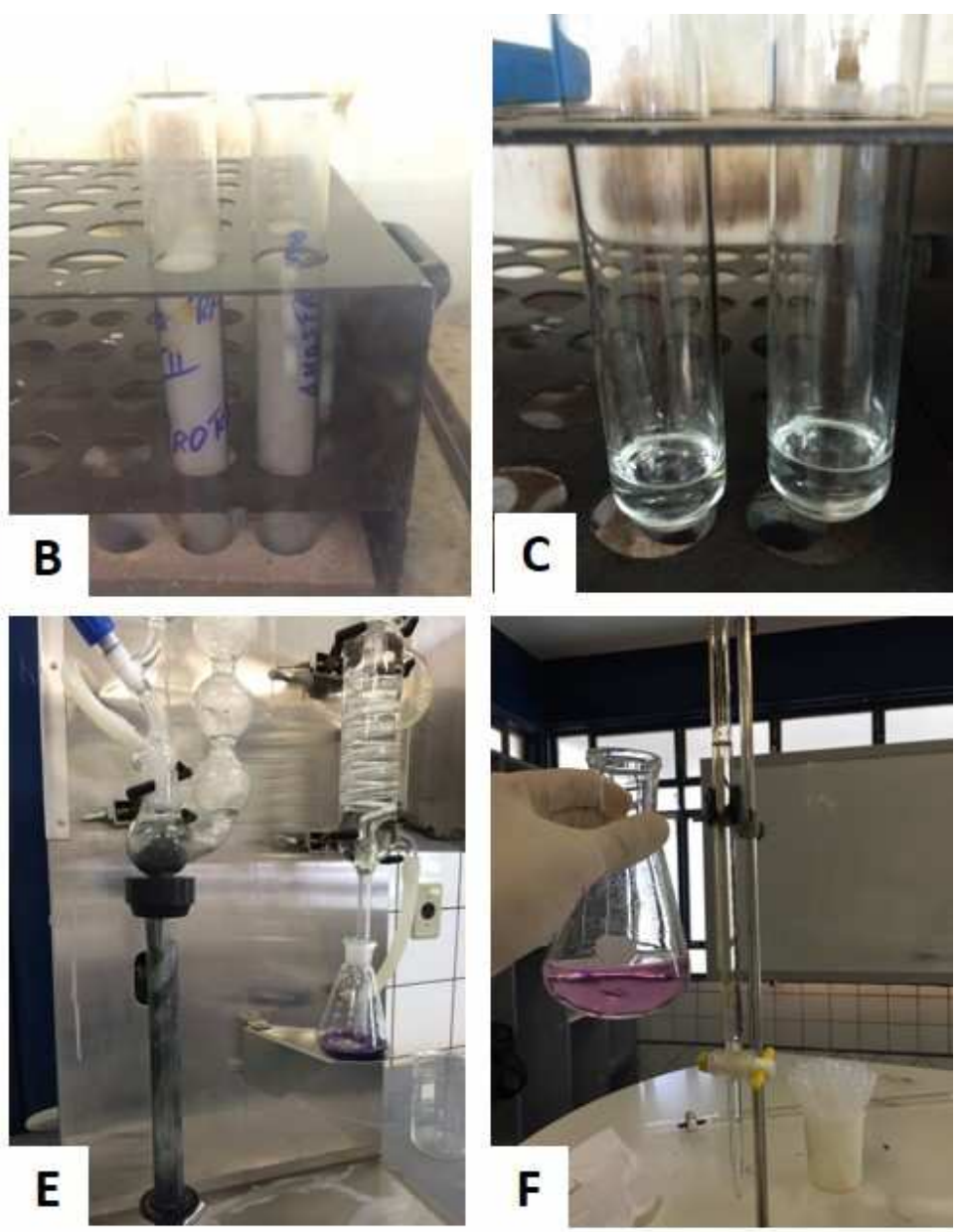

FIGURA 1 - Sequência de eventos para quantificação de proteínas: (A) Em detalhe, tubo de Kjeldahl com amostra de WP + solução catalizadora e ácido sulfúrico $\mathrm{H}_{2} \mathrm{SO}_{4}$ concentrado. (B) Processo de digestão da amostra, após alguns minutos de queima começa a liberação de gás carbônico. (C) Após a queima total e resfriamento da amostra é gerada uma solução translúcida, límpida. (D) Processo de destilação, onde foi acrescentado $10 \mathrm{~mL}$ de Hidróxido de sódio $\mathrm{NaOH} 50 \%$, enquanto o aparelho aquecia. (E) Início do aquecimento, da evaporação da amônia e formação do boroato de amônia capturado no erlenmeyer com solução de ácido bórico + solução indicadora na saída do destilador. (F) Titulação para a determinação da dosagem de nitrogênio e viragem onde foi determinada a dosagem de nitrogênio total. Fonte: Própria dos autores (2015).

\section{RESULTADOS E DISCUSSÃO}

Os resultados (Tabela 1), demonstram em algumas das amostras mais utilizadas pelos atletas e até mesmo pessoas comuns uma variação muito grande em relação à rotulagem do produto, ou seja, o fabricante determinou no rótulo um 
valor proteico que no presente estudo ficou comprovado uma variação superior ao aceitável pela ANVISA.

TABELA 1 - Teor declarado de proteínas por cada fabricante e os resultados obtidos por meio da análise de Whey Protein

\begin{tabular}{|c|c|c|c|c|c|c|}
\hline AMOSTRAS & A & B & C & D & $\mathbf{E}$ & $\mathbf{F}$ \\
\hline Porção recomendada pelo fabricante & $30,00 \mathrm{~g}$ & $62,00 \mathrm{~g}$ & $50,00 \mathrm{~g}$ & $50,00 \mathrm{~g}$ & $60,00 \mathrm{~g}$ & $30,00 \mathrm{~g}$ \\
\hline Teor de proteínas na descrição nutricional & $24,00 \mathrm{~g}$ & $55,00 \mathrm{~g}$ & $46,00 \mathrm{~g}$ & $40,00 \mathrm{~g}$ & $51,00 \mathrm{~g}$ & $26,70 \mathrm{~g}$ \\
\hline Teor de proteínas por $100 \mathrm{~g}$ de produto & $80,00 \mathrm{~g}$ & $88,71 \mathrm{~g}$ & $92,00 \mathrm{~g}$ & $80,00 \mathrm{~g}$ & $85,00 \mathrm{~g}$ & $89,00 \mathrm{~g}$ \\
\hline $\begin{array}{l}\text { Teor proteico médio encontrado em \% / } 100 \\
\text { g do produto }\end{array}$ & $71,75 \%$ & $70,00 \%$ & $36,60 \%$ & $43,03 \%$ & $76,75 \%$ & $73,21 \%$ \\
\hline $\begin{array}{l}\text { Teor proteico médio encontrado em (g) do } \\
\text { produto (Dose) }\end{array}$ & $21,52 \mathrm{~g}$ & $43,40 \mathrm{~g}$ & $18,30 \mathrm{~g}$ & $21,51 \mathrm{~g}$ & $46,05 \mathrm{~g}$ & $21,96 \mathrm{~g}$ \\
\hline Diferença em (\%) padrão & $-10,33 \%$ & $-21,09 \%$ & $-60,21 \%$ & $-46,21 \%$ & $-9,70 \%$ & $-17,74 \%$ \\
\hline
\end{tabular}

O principal foco do uso desse tipo de suplementação é o ganho de massa magra (TAHAVORGAR et al., 2014), melhora na capacidade física, emagrecimento (LUHOVVY et al., 2007) e o aumento da imunidade (BOUNOUS \& KONGSHAVN, 1983). Todos esses benefícios são gerados pela ingesta do Whey Protein (ARAÚJO \& SOARES, 1999) em doses adequadas.

Os dados apresentados (Gráfico 1), referem-se às análises realizadas neste trabalho, quanto a RDC n 360/2003 da ANVISA, que relaciona o valor de proteínas presente nas amostras analisadas dos declarados por cada fabricante em suas informações nutricionais e que devem ter a diferença de no máximo $20 \%$, para mais ou para menos do que está declarado.

\section{TEOR DE PROTEÍNAS}

- TEOR DE PROTEÍNAS DECLARADO EM (g) — TEOR DE PROTEÍNAS ENCONTRADO EM (g)

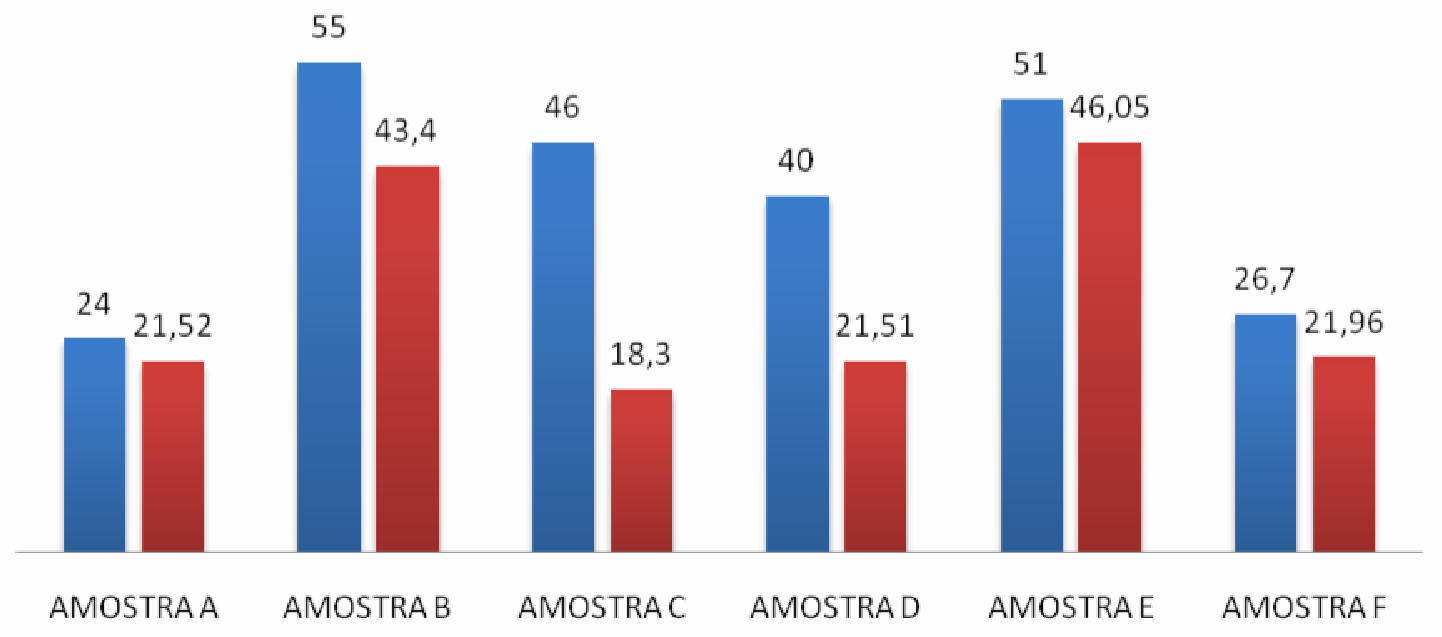

GRÁFICO 1: Comparativo do teor de proteínas declarado pelos fabricantes e o valor encontrado na análise.

Analisando os dados (Gráfico 1), nota-se a diferença de valores na rotulagem dos produtos, na qual nenhuma das amostras analisadas apresentam realmente 0 
valor descrito em suas informações. A análise (Gráfico 2), demonstra a diferença de percentual obtida em relação aos valores declarados nas informações nutricionais, as amostras $\mathrm{A}, \mathrm{E}$ e $\mathrm{F}$ apresentam um valor encontrado de proteínas dentro do padrão aceitável da RDC 360, já as amostras B, C e D ultrapassam esse limite de $20 \%$.

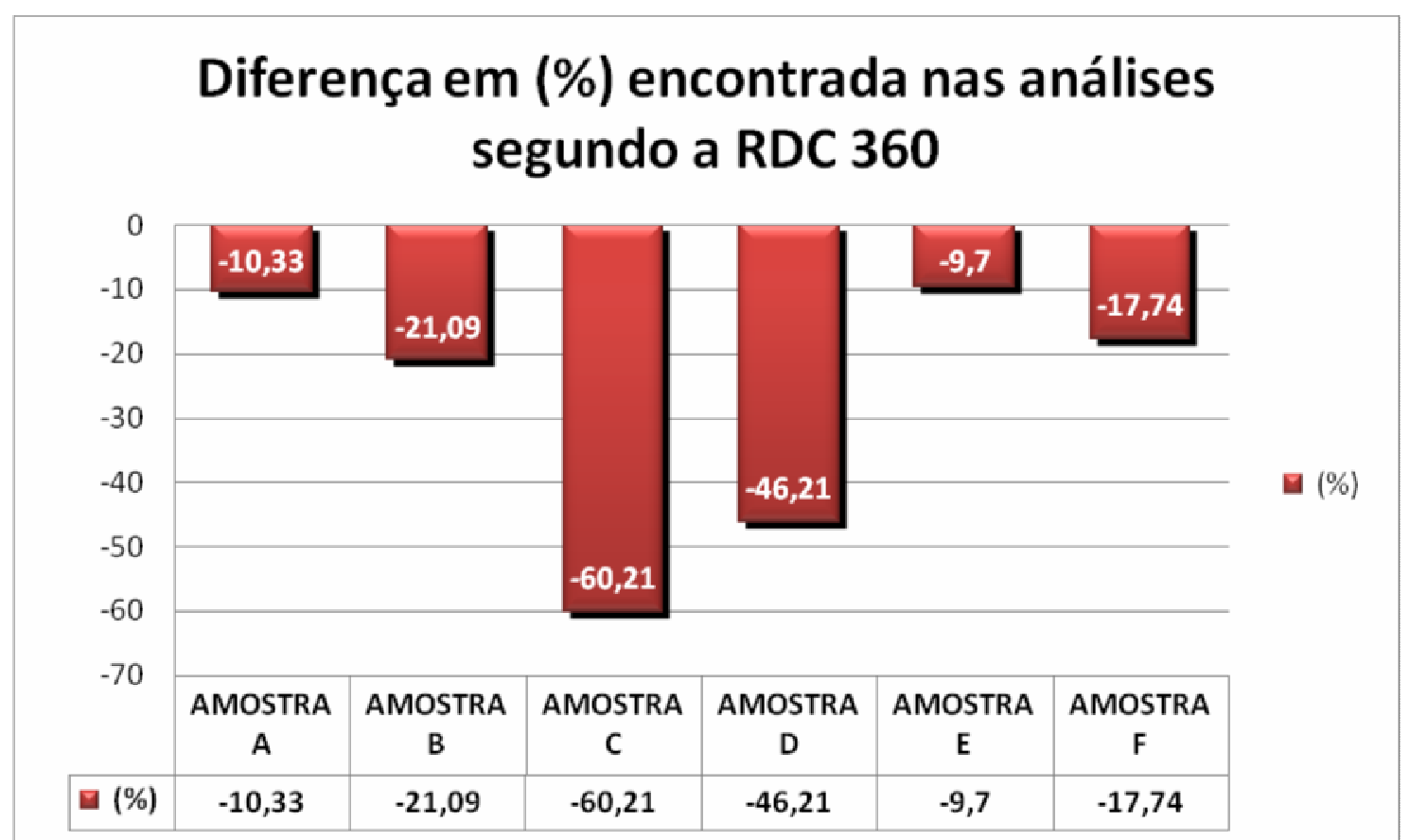

GRÁFICO 2: Porcentagem (\%) encontrada de cada amostra dentro do limite de $20 \%$ para mais ou para menos.

No presente trabalho os resultados obtidos estão de acordo com a classificação de suplemento proteico para atletas, segundo regulamentação da ANVISA no artigo $8^{\circ}$ da RDC no 18/2010, que diz: Para que um produto possa ser comercializado nesta categoria deve apresentar $10 \mathrm{~g}$ (dez gramas) como quantidade mínima de proteínas (ANVISA, 2010). Todas as amostras analisadas estão de acordo com essa RDC, pois possuem valores superiores aos $10 \mathrm{~g}$ de proteínas por porção.

A preocupação está justamente nesse quesito, pois se o usuário compra determinada proteína que vem com um teor abaixo do descrito, os resultados não serão obtidos com sucesso, pois os benefícios estão relacionados com a quantidade de proteína ingerida pelo usuário (OLIVEIRA et al., 2009).

As amostras analisadas apesar de estarem de acordo com algumas exigências da ANVISA demonstram a falta de fiscalização e de uma regulamentação mais rígida, pois ferem até mesmo o código de defesa do consumidor (Lei 8.078, de 11 de setembro de 1990, do Ministério da Justiça - Código de Proteção e Defesa do Consumidor), na qual o consumidor adquire, nesse caso um produto com o teor de proteínas inferior ao descrito nas informações nutricionais. De acordo com INGELFINGER (2008), enquanto não houver um controle na determinação de proteínas, os consumidores e a indústria estarão correndo o risco de mais adulterações. 


\section{CONCLUSÃO}

Nenhuma das amostras analisadas demonstrou o mesmo teor proteico daquele reportado pelo fabricante. Os resultados obtidos neste trabalho mostram uma tendência crítica que tem aumentado por falta de um maior controle de qualidade na produção do WP, ainda que, em um passado próximo, houve uma avaliação prévia por parte da ANVISA e, inclusive, retirou de circulação muitas marcas que comercializavam produtos com teor proteico além daquele reportado na embalagem. Ademais, dado a popularidade do produto em questão, torna-se razoável sugerir um maior rigor nas análises para garantir que o consumidor esteja adquirindo um produto com as características que realmente os atenda.

\section{REFERÊNCIAS}

ADAMS R, L.; BROUGHTON K, S. Insulinotropic Effects of Whey: Mechanisms of Action, Recent Clinical Trials, and Clinical Applications. Ann Nutr Metab., v. 69, p. 56-63, 2016. Disponível em: < https://www.ncbi.nlm.nih.gov/pubmed/27529642/> doi: $10.1159 / 000448665$

AJAREM, J.; ALLAM, A. A.; EBAID, H.; MAODAA, S. N.; AL-SOBEAI, S. M.; RADY, A. M.; SABRI, M. I. Neurochemical, structural and neurobehavioral evidence of neuronal protection by whey proteins in diabetic albino mice. Behavioral and Brain Functions., v. 11, n. $7, \quad$ p. 1-8, 2015. Disponível em: < http://www.ncbi.nlm.nih.gov/pmc/articles/PMC4331294/> doi: 10.1186/s12993-0150053-0

AKHAVAN, T.; LUHOVYY, B.L.; BROWN, P.H.; CHO, C.E.; ANDERSON, G. H. Mechanism of action of pre-meal consumption of whey protein on glycemic control in young adults. J Nutr Biochem., v. 25, n. 1, p. 36-43, 2014. Disponível em: < http://linkinghub.elsevier.com/retrieve/pii/S0955-2863(13)00183-6> doi: http://dx.doi.org/10.1016/j.jnutbio.2013.08.012

ANVISA, Resolução RDC o 360, de 23 de dezembro de 2003 <http://portal.anvisa.gov.br/wps/wcm/connect/ec3966804ac02cf1962abfa337abae9d/ Resolucao_RDC_n_360de_23_de_dezembro_de_2003.pdf?MOD=AJPERES>. Acesso em 15 de Mai de 2014, 00:44:33.

ANVISA, Resolução RDC no 18 artigo 80, de 2010.

<http://portal.anvisa.gov.br/wps/wcm/connect/65f5b80047457f258ad7de3fbc4c6735/ RDC+dos+Atletas+-+Dicol.pdf?MOD=AJPERES>. Acesso em 20 de Out de 2014, 00:30:20.

ARAÚJO, A. C; SOARES, Y. N. Perfil de utilização de repositores proteicos nas academias de Belém, Pará. Revista de Nutrição. Campinas, v. 12, n. 1, p.12-19, 1999. Disponível em: < http://bases.bireme.br/cgibin/wxislind.exe/iah/online/?/sisScript=iah/iah. $x i s \& s r c=g o o g l e \& b a s e=L I L A C S \& l a n g=p$ \&nextAction=Ink\&exprSearch=302177\&indexSearch=ID>

BURD, N. A.; YANG, Y.; MOORE, D. R.; TANG, J. E.; TARNOPOLSKY, M. A.; PHILLIPS, S. M. Greater stimulation of myofibrillar protein synthesis with ingestion of whey protein isolate $v$. micellar casein at rest and after resistance exercise in elderly 
men', British Journal of Nutrition, v. 108, n. 6, p. 958-962, 2012. Disponível em: < https://www.ncbi.nlm.nih.gov/pubmed/22289570> doi: $10.1017 /$ S0007114511006271.

BOUNOUS, G.; KONGSHAVN, PA. Influence of dietary protein on the immune system of mice. J Nutr. p. 1747-1755, 1983. Disponível em: < http://jn.nutrition.org/content/113/7/1415.long>.

$\mathrm{CECCHI}, \mathrm{H}$. M. Fundamentos teóricos e práticos em análise de alimentos. $2 \mathrm{a}$ Ed.rev. Campinas: Editora Unicamp. p. 207, 2003.

DEVLIN, T. M. Manual de Bioquímica com correlações clínicas. $7^{a}$ ed. São Paulo: BLUCHER, 2011, 1252p.

DEVRIES, M. C.; PHILLIPS, S. M. Supplemental Protein in Support of Muscle Mass and Health: Advantage Whey. Journal of Food Science, v. 80, p. A8-A15, 2015. Disponível em: http://onlinelibrary.wiley.com/doi/10.1111/17503841.12802/abstract;jsessionid=541C0AB0B619538E2D1B5D6E30ADB375.f04t04 doi:10.1111/1750-3841.12802

DRAGANIDIS, D.; KARAGOUNIS, G, L.; ATHANAILIDIS, I.; CHATZINIKOLAOU, A.; JAMURTAS, Z, A.; FATOUROUS, G, I. Inflammaging and Skeletal Muscle: Can Protein Intake Make a Difference?. The Journal of Nutrition., v. 0, n. 0, p. 1-13, 2016. Disponível em: < http://jn.nutrition.org/content/early/2016/08/31/jn.116.230912.long> doi: $10.3945 /$ jn. 116.230912

FARUP, J.; RAHBEK, K, S.; RIS, S.; VENDELBO, H, M.; PAOLI, F.; VISSING, K. Influence of exercise contraction mode and protein supplementation on human skeletal muscle satellite cell content and muscle fiber growth. Journal of Applied Physiology., v. 117, n. 8, p. 898-909, 2014. Disponível em: <http://jap.physiology.org/content/117/8/898> doi: 10.1152/japplphysiol.00261.2014

INGELFINGER, JR. Melamine and the global implications of food contamination. N English J Med, p. 359-385, 2008. Disponível em: < http://www.nejm.org/doi/full/10.1056/NEJMp0808410 > doi: 10.1056/NEJMp0808410

JAKUBOWICZ, D.; FROY, O. Biochemical and metabolic mechanisms by which dietary whey protein may combat obesity and Type 2 diabetes. Journal of Nutritional Biochemistry., v. 24, n. 1, p. 1 - 5, 2013. Disponível em: < http://www.jnutbio.com/article/S0955-2863(12)00201-X/abstract> doi: http://dx.doi.org/10.1016/j.jnutbio.2012.07.008

KRESSLER, J.; BURNS, P. A.; BETANCOURT, L.; NASH, M. S. Circuit training and protein supplementation in persons with chronic tetraplegia. Medicine and Science in Sports and Exercise, v. 46, n. 7, p. 1277-1284, 2014. Disponível em: < https://www.ncbi.nlm.nih.gov/pubmed/24389521>

DOI: $10.1249 /$ MSS.0000000000000250 
LÖNNERDAL, B. Nutritional and physiologic significance of human milk proteins. Am J Clin Nutr, v. 77, n. 6, p. 1537-1543, 2003. Disponível em: < http://ajcn.nutrition.org/content/77/6/1537S.long>

LUHOVVY, B. L.; AKHAVAN, T.; ANDERSON, G.H. Whey Proteins in the Regulation of Food Intake and Satiety. Journal of the American College of Nutrition, v. 26, n. 6, p. 712-718, 2007. Disponível em: < https://www.researchgate.net/publication/5664194_Whey_Proteins_in_the_Regulatio n_of_Food_Intake_and_Satiety>

OLIVEIRA, A. F.; FATEU, S. C. E.; SOARES, M. B.; CíRICO, D. Avaliação Nutricional de praticantes de musculação com objetivo de hipertrofia muscular do município de Cascavel, PR. Colloquium Vitae. v. 1, n. 1, p. 44-52, 2009. Disponível em:

http://web.b.ebscohost.com/abstract?direct=true\&profile=ehost\&scope=site\&authtype

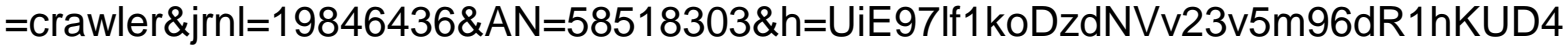
2kfb\%2fzr\%2fjWIQVbdflUI8VKUW8mvAjUdSvMNjEc5hMGbXn68GAzvPwTQ\%3d\%3 $\mathrm{d} \& \mathrm{crl}=\mathrm{f} \&$ resultNs=AdminWebAuth\&resultLocal=ErrCrlNotAuth\&crlhashurl=login.. asp $x$ \%3fdirect\%3dtrue\%26profile\%3dehost\%26scope\%3dsite\%26authtype\%3dcrawler\% 26jrnl\%3d19846436\%26AN\%3d58518303>

PAL, S.; RADAVELLI-BAGATINI, S. The effects of whey protein on cardiometabolic risk factors. Obes Rev., v. 14, p. 324-343, 2013. Disponível em: < http://onlinelibrary. wiley.com/doi/10.1111/obr.12005/abstract;jsessionid=87253E52D3 2FB680CAF3D98E04141C70.f03t03>.

SALZANO JR, I. Nutritional supplements: practical applications in sports, human performance and life extension. In: Symposium series. p. 1996-2002. Disponível em: < http://www.scielo.br/scielo.php?script=sci_nlinks\&ref=000066\&pid=S1415$5273200600040000700001 \&$ lng=es $>$.

TAHAVORGAR, A.; VAFA, M.; SHIDFAR, F.; GOHARI, M.; HEYDARI, I. Whey protein preloads are more beneficial than soy protein preloads in regulating appetite, calorie intake, anthropometry, and body composition of overweight and obese men. Nutrition Research, v. 34, n. 10, p. 856 - 861, 2014. Disponível em: < http://www.nrjournal.com/article/S0271-5317(14)00166-3/abstract>

DOI: http://dx.doi.org/10.1016/j.nutres.2014.08.015

TOSUKHOWONG, P.; BOONLA, C.; DISSAYABUTRA, T.; KAEWWILAI, L.; MUENSRI, S.; CHOTIPANICH, C.; JOUTSA, J.; RINNE, J.; BHIDAYASIRI, R. Biochemical and clinical effects of whey protein supplementation in parkinson's disease: A pilot study. Journal of the Neurological Sciences., v. 367, p. 162-170, 2016. Disponível em: < http://www.jns-journal.com/article/S0022-510X(16)303252/abstract> doi: http://dx.doi.org/10.1016/j.jns.2016.05.056 